\title{
STRATEGY
}

http://www.smallbusinessinstitute.biz

\section{The economic implications of clustering on Hispanic entrepreneurship in the US}

\author{
Ariana Torres ${ }^{1}$, Michael S. Delgado ${ }^{2}$, Maria I. Marshall ${ }^{3}$ \\ ${ }^{1}$ Purdue University, Department of Agricultural Economics, 403 W. State Street, KRAN 606, West Lafayette, IN 47907, USA, torres2@purdue. \\ $e d u$ \\ ${ }^{2}$ Purdue University, Department of Agricultural Economics, 403 W. State Street, KRAN 617, West Lafayette, IN 47907, USA, delgado2@pur- \\ due.edu \\ ${ }^{3}$ Purdue University, Department of Agricultural Economics, 403 W. State Street, KRAN 778, West Lafayette, IN 47907, USA, mimarsha@, \\ purdue.edu \\ www.jsbs.org
}

Keywords:

Hispanic entrepreneurship, Endogeneity, Generalized propensity score, Intergenerational mobility

\section{A B S T R A C T}

\begin{abstract}
This article assesses the effect of Hispanic clustering on Hispanic self-employment in the US and the extent to which endogenous social factors within a cluster may encourage Hispanics to start a business. We address key identification issues in the clustering literature by applying a series of robust econometric techniques to US census data. The study provides empirical evidence on the role of Hispanic clustering on Hispanic entrepreneurship. This article also tackles the constructs of Hispanic entrepreneurial heterogeneity and suggests the clustering of second-generation Hispanics as a potential indicator of the Hispanic entrepreneurial environment. The study derives insight on the economic implications of Hispanic clustering and its benefits and suggests policy recommendations to promote success among Hispanic entrepreneurs. We propose that generational differences across Hispanics is not merely an ethnic control variable, but rather an important factor for the design of strategies and incentives at the federal, state, and local level.
\end{abstract}

\section{Introduction}

The Hispanic labor force is on track to increase by $77 \%$ over the 2000-2020 period (Suro \& Passel, 2003), maintaining its status as the largest US minority (Liu, 2012). A growing Hispanic population is likely to contribute to an increase in the number of Hispanic-owned businesses, which are already outpacing the growth of non-Hispanic businesses, according to data from Census Bureau's Survey of Business Owners. By 2015, over 4 million Hispanic businesses reported $\$ 661$ billion in sales (USHCC, 2015); most of these businesses are located in Hispanic clusters, where the access to ethnic clientele, low-cost labor, and key suppliers is crucial for their success.

It is unclear if the benefits of living in clusters motivates or deter Hispanics to start a business. On the one hand, there is evidence that Hispanic self-employment is highly influenced by the community (Fairlie, 2004; Fisher \& Lewin, 2018). In close proximity or in clusters, Hispanics are more likely to know each other and develop socioeconomic ties (Kim \& Aldrich, 2005). Other researchers have found the relationship between Hispanic clustering is

Journal of Small Business Strategy

2021, Vol. 31, No. 03, 72-87

ISSN: 1081-8510 (Print) 2380-1751 (Online)

(C) Copyright 2021 Small Business Institute ${ }^{\circledR}$ either not correlated or negatively correlated with Hispanic self-employment (Liu, 2012; Yuengert, 1995). Here, we address this open question by investigating the impact of Hispanic clustering on Hispanics' choice to become entrepreneurs.

Our secondary goal is to address the role of heterogeneity on Hispanic entrepreneurship. This article advances the literature by incorporating Hispanic heterogeneity and derives insight on the labor choices for different generations of Hispanics. While Hispanic heterogeneity is, to a large extent, related to the place of birth (Dávila \& Mora, 2013), we show that generational differences are also important factors contributing to Hispanic diversity. Generations are measured via categorical variables that combine place of birth and the length of time the individual has been in the US. We expect differences in economic behavior across foreign- and US-born Hispanics, and across different generations (e.g. first, 1.5, second, and third generation).

We develop an identification strategy that allows us to address several potential sources of endogeneity. Specifically, we use a series of robust econometric techniques to control for macroeconomic, individual, and unobserved peer influences that may affect Hispanic self-employment; these are issues that have not yet been addressed in the cur-

APA Citation Information: Torres, A., Delgado, M. S., \& Marshall, M. I.. (2021). The economic implications of clustering on Hispanic entrepreneurship in the US. Journal of Small Business Strategy, 31(3), 72-87. 
rent Hispanic entrepreneurship literature. We used an extensive list of covariates at the individual and community level control for numerous factors. We then use instrumental variables to control for unobserved macroeconomic factors leading Hispanics to sort into different regions (i.e. Public Use Microdata Areas (PUMAs)) that may also be correlated with the decision to be an entrepreneur. Lastly, we use a generalized propensity score (GPS) approach to adjust for non-randomness in the effect of Hispanic clustering on Hispanic self-employment.

We contribute to the literature in three ways. First, we develop robust econometric models on the effect of Hispanic clustering on Hispanic entrepreneurship, allowing us to push past empirical hurdles such as self-selection into clusters and the presence of unobservable factors. Second, we provide empirical evidence that the probability of Hispanic entrepreneurship responds to specific levels of Hispanic clustering. Lastly, we tackle the constructs of Hispanic heterogeneity and find potential indicators for the Hispanic entrepreneurial environment. Policymakers, scholars, and stakeholders can use our findings to fuel future generations of Hispanic entrepreneurs. If clustering is relevant for Hispanic entrepreneurship, public and private programs are more likely to effectively increase the success of Hispanic entrepreneurs if targeted through community linkages. Lastly, one-size-fits-all policies disregarding the heterogeneity among Hispanics will likely have contrasting implications for certain groups.

\section{Literature Review}

\section{Hispanic Self-Employment}

The US Census Bureau defines self-employed individuals to be those who "operate their own business, professional practice, farm, or who in any other way regularly work independently to earn a living." Historically, self-employment is an important means through which immigrants obtain economic mobility in the US (Fairlie \& Meyer, 1996), especially for those facing labor market barriers (Shinnar \& Young, 2008). Major drivers of self-employment are regional factors, age, marital status, human capital, and other individual, family, business, and community characteristics (Liu, 2012; Robinson \& Sexton, 1994). The literature has reported Hispanics are more likely to start a business than non-Hispanics, especially in retail, services, and construction industries (Liu, 2012). However, Hispanic-owned businesses tend to have lower returns than non-Hispanic entrepreneurs, enter industries with lower barriers, and report additional sources of income other than self-employment (Evans \& Leighton, 1989).
There is evidence that immigrant self-employment is highly influenced by the socioeconomic environment. Factors influencing the likelihood of self-employment are the characteristics of Hispanic communities; for instance, the level of educational attainment in the community, type of predominant industries, housing prices, population diversity and density, and urban or metro status (Parker, 2004). According to Fairlie (2004b), the decision to be an entrepreneur is positively correlated with the agglomeration of Hispanics. While Wang (2010) suggests that Hispanics are more likely to be self-employed in areas with a high proportion of Hispanics because of community resources and opportunities, Liu (2012) does not find that Hispanic-concentrated areas are correlated with higher rates of Hispanic self-employment. Yuengert (1995) reports no correlation.

\section{Hispanic Clustering}

Hispanics are likely to cluster in areas where other Hispanics live and work (Stark, 1991). In clusters, successful Hispanics are observed and copied by others in their pursuit of achieving economic mobility (Danes et al., 2008). Individuals sharing similar characteristics, such as ethnicity, are more likely to know each other and link their socioeconomic activities (Kim \& Aldrich, 2005). The fact that clusters tend to remain stable over time encourage the creation of entrepreneurial ecosystems (Amit \& Muller, 1995; Fisher \& Lewin, 2018).

The push and pull theory of entrepreneurship (Amit \& Muller, 1995) helps us understand that the choice to start a business is a function of the individual's motivational factors. The framework is useful to accommodate the assumption that not one all-encompassing model can explain labor choices of immigrants (Clark \& Drinkwater, 2000). Factors such as the demographic context, personal characteristics, and living and working environment shape labor choices (Shapero \& Sokol, 1982). This overarching framework incorporates the opposing pushing and pulling mechanisms driving the choice of self-employment among Hispanics (Cromie, 1987; Fisher \& Lewin, 2018).

Hispanic clusters can act as a pull factor by motivating Hispanics to start a business. Clusters can provide entrepreneurs with access to ethnic clientele, low-cost labor, and key suppliers. Hispanic clustering can also be a push factor by forcing Hispanics into self-employment (Reimers, 1983). Economically depressed communities with high unemployment can push Hispanics to start a business as the only way to achieve economic mobility (Kramer Mills et al., 2018). This is especially true among those facing labor discrimination and a lack of educational credentials.

Few scholars have studied the mechanisms affecting 
the correlation between Hispanic clustering and the creation of Hispanic-owned businesses. We posit that inconsistencies in the literature on the relationship between clustering and entrepreneurship may be due to the lumping of Hispanics into a homogenous group, which fails to account for the heterogeneity among Hispanics from different generations (Bradley, 2004). Generational heterogeneity is a key trait likely to affect the economic behavior of Hispanics (Portes \& Rumbaut, 2003). While most of the current entrepreneurship studies have focused on foreign-born Hispanic entrepreneurs (Yuengert, 1995), the one-size-fits-all findings tend to overlook Hispanic heterogeneity and may lack generality in the results.

\section{Method}

\section{Data and Sample}

Data comes from the 2010 US Census, which is the latest count of every person living in the US This study takes advantage of the large sample size documented by the census to provide a representative sample of Hispanics who are self-employed. We use the person weights in the census database to make the sample representative of the national population.

The sample contains 307,698 Hispanics living in 2,043 Public Use Microdata Areas (PUMAs) across the US. The choice of PUMA as the spatial scale is motivated by data availability, as PUMAs are the smallest geographic unit available in the census. Although PUMAs can include large areas with a low population, such as in rural areas, urban areas may contain one or more PUMAs. Thus, PUMAs are large geographic areas, but they are also small enough to capture the environment in which individuals interact.

The sample contains Hispanics between 18 and 70 years old, which were categorized by generation such as first, 1.5, second, and third generation. First generation Hispanics are individuals born in Latin America that arrived in the US at any age greater than 16 years. Generation 1.5 consists of Hispanics born in Latin America that arrived in the US at a maximum age of 16 years0F. The countries of origin for $1 \mathrm{st}$ and 1.5 generation Hispanics include Puerto Rico, Cuba, Mexico, Caribe (the Dominican Republic, Haiti, Jamaica and the West Indies), Central America (Belize, Costa Rica, El Salvador, Guatemala, Honduras, Nicaragua and Panama), and South America (Argentina, Bolivia, Brazil, Chile, Colombia, Ecuador, French Guiana, Guyana, Paraguay, Peru, Suriname, Uruguay and Venezuela). Second-generation Hispanics include individuals born in the US with either parent born in Latin America. Lastly, third-generation Hispanics include individuals born in the
US, but report Hispanic ethnicity or ancestry. In our sample, $38 \%$ are first generation, and the 1.5 , second, and third generations make up 14,7 , and $41 \%$ of the sample, respectively.

\section{A Probit Model of the Decision to be an Entrepreneur}

To understand how living in Hispanic clusters influences the decision for a Hispanic individual to become an entrepreneur, we use a probit regression model

$$
\operatorname{Pr}\left(Y_{i}=1 \mid X_{i}\right)=\Phi\left(\beta_{0}+X_{1 i} \beta_{1}+X_{2 i} \beta_{2}\right), \quad i=1,2, \ldots, N
$$

where the dependent variable if individual self-reported as being employed in his/her own. The Hispanic clustering variables we are interested in are: the share of the population living in individual 's PUMA that is Hispanic, representing the degree of Hispanic clustering within the PUMA; the share of the population (of any race or ethnicity) in the PUMA that is self-employed; and the share of the Hispanic population in the PUMA that is self-employed. The vector is a set of individual-level and PUMA-level control variables. The parameter vector is to be estimated, and is the standard normal probability distribution function. This empirical model fits into the scope of models in the neighborhood effects literature (e.g., Durlauf, 2004; Graham, 2016), of which the central question pertains to the extent to which estimation of the regression model can be plausibly interpreted as causal.

The first Hispanic clustering variable, the share of Hispanics living in the PUMA, captures the clustering of all Hispanics. The last two clustering variables, the percent of self-employed individuals in the PUMA and the percent of all Hispanics in the PUMA that are self-employed, measure the extent to which there are endogenous clustering factors within the PUMA that encourage Hispanic individuals to be self-employed. We anticipate that any increase in self-employment within the PUMA will lead to a significant increase in the probability that a Hispanic individual becomes self-employed, with a particularly strong effect coming from the share of other Hispanics in the PUMA that are self-employed. In additional specifications of the model, we interact these clustering variables with generational indicators, to understand the extent to which these clustering effects might be heterogeneous across Hispanic generations. Similarly, Lazear (1999) calculates immigrant clustering by the proportion of individuals in a geographic area.

Identification of the social effects comes from several sources. First, we control for an extensive set of individual-specific and PUMA-specific factors that affect both the decision to become an entrepreneur and the shares of the population within each PUMA that are Hispanic and/or are 
entrepreneurs (i.e., the variables in ). Our data include an extensive list of covariates measured at the individual and PUMA levels, which allows us to control for numerous factors that might otherwise confound identification. At the individual level, we observe many individual, household, and family background demographic variables, which include gender, age, household income, marital status, the number of children, English and Spanish language proficiency, education, access to mortgage, industry, metropolitan status, the education level and employment status of the individual's parents and spouse, and the ethnicity of the individual's spouse. At higher levels of spatial aggregation, we control for broad geographic differences via eight US territory division indicators from the Bureau of Economic Analysis (BEA): New England, Mideast, Great Lakes, Plains, Southeast, Southwest, Rocky Mountain, and Far West. Alaska and Hawaii are excluded as the subsample does not report Hispanics within the age group living in these states. See the Supplemental Appendix for more details. At the PUMA level, we control for the share of the population in the PUMA that is white or black (i.e., US-born, non-Hispanic), as well as the violent crime rate and the proportion of the population that is college-educated, unemployed, and self-employed. In total, these variables control for numerous individual-level and PUMA-level attributes that might drive self-selection into becoming an entrepreneur or the sorting of individuals into different neighborhoods (i.e., PUMAs).

Table 1 presents a complete list of control variables included in our analysis. These variables control for the contextual socioeconomic status of each PUMA. Including other ethnic and racial groups permits us to control for potential labor segregation (Charles, 2003) since it is likely that other race and ethnic clusters affect the creation of Hispanic-owned businesses. Further, a high negative correlation between percent Hispanic and percent white (-0.73) validates our decision to include the share of other races and ethnicities in the list of explanatory variables.

The second source of identification comes from the nonlinearity inherent in the probit specification (Brock \& Durlauf, 2001; 2007). According to Manski (1993), there are three types of variables that drive economic activity or, in our case, the decision by a Hispanic individual to become an entrepreneur. One set of variables is the endogenous social effects - the probability of self-employment in response to Hispanic clustering, self-employment, and Hispanic self-employment in the group. The other two sets of variables are the exogenous group effects - the probability of self-employment varies with the socioeconomic composition of the PUMA and the exogenous individual effects - the probability of self-employment varies according to individual attributes, such as language proficiency or edu- cation. Brock and Durlauf $(2001 ; 2007)$ show that nonlinearities - which are inherent to the probit specification - are a critical source of identification of endogenous social effects from contextual group characteristics. In other words, the non-identification result in Manski (1993) depends critically on the assumed linearity of the regression function (among other assumptions; see for instance Durlauf, 2004). Hence, while the interplay between these types of variables are complex, the probit structural form aids us in separating these effects from one another.

To the extent that our set of controls is not sufficient for eliminating bias caused by omitted variables, we deploy an instrumental variables probit and generalized propensity score approach as auxiliary models. While our set of control variables is extensive, it is possible that unobservable macroeconomic factors lead to systemic sorting of Hispanics into different PUMAs that would render the share of Hispanics in the PUMA to be endogenous. To guard against this possibility, we deploy the two-stage instrumental variable approach of Card (2009). The advantage of the generalized propensity score model is that the flexible functional form may be more robust if the single-index form of the probit is overly restrictive; in other words, the generalized propensity score approach is a flexible way of adjusting for observable differences that might be a source of self-selection of Hispanics into entrepreneurship.

We use two instrumental variables designed to extract the exogenous variation in Hispanic clustering (Card 2009). The first instrument is the supply-push component of immigration inflows, capturing the tendency of immigrants to move to pre-existing clusters and controlling for macroeconomic shocks that increase the attractiveness of a city and leading to immigrant inflows. Specifically, the instrument measures the expected number of Hispanics going to a PUMA, which is the multiple fraction of all arriving Hispanics who choose to live in a PUMA (e.g. the share of immigrants in a PUMA in an initial period 2000) $(\lambda \mathrm{s}=\mathrm{Ms} /$ MUS) and the total number of new Hispanics to the US in 2010 relative to 2000 ( $\Delta$ MUS). The instrument is multiplied by the fixed multiple of the fraction of immigrants in the PUMA. In other words, the instrument captures how current Hispanic clustering is a product of historical settlement patterns of Hispanics and newly arriving Hispanics in a PUMA.

Additional instruments for Hispanic clustering are based on weather (Coates \& Gindling, 2010; Miguel et al., 2004). We use heating (and cooling) degree days as measures of climatic comfort; these data were collected from the National Ocean and Atmospheric Administration (NOAA) for each county. Heating degree-days express the frequency in which the temperature falls low enough that heating is 
Table 1
List of dependent and explanatory variables

Variable

Description

selfemp ${ }^{\mathrm{a}} \quad 1=$ if individual is self-employed, 0 otherwise. Reported that is employed $(\mathrm{empstat}=1)$ and works for own enterprise $(\mathrm{classwkr}=1)$

platino average percentage share of Hispanic at the PUMA level

lincome $\quad \log$ of average household income

age age in years

agetwo square of age in years

crime violent crime rate per 100,000 at the state level

nchild average number of children in Hispanic household

married $^{\mathrm{a}} \quad 1=$ if individual is married with either present or absent spouse

speakenglish $^{\mathrm{a}} \quad 1=$ if individual speaks English well, very well, or only English

spanish $^{\mathrm{a}} \quad 1=$ if individual speaks Spanish in household, 0 otherwise

female $^{\mathrm{a}} \quad 1=$ if individual is female

college $^{\mathrm{a}} \quad 1=$ if individual has 1 year of college or more

metroarea $^{\mathrm{a}} \quad 1=$ if individual lives in a metro area

accessmort $^{\mathrm{a}} \quad 1=$ if individual reports to have a mortgage or contract to purchase

collparent $^{\mathrm{a}} \quad 1=$ if either mother or father have some college education or graduate studies

selfemppar $^{\mathrm{a}} \quad 1=$ if either mother or father is self-employed, 0 otherwise

employsp $^{\mathrm{a}} \quad 1=$ if spouse is employed

sphispanic $^{\text {a }} \quad 1=$ if spouse is Hispanic

collspouse $^{\mathrm{a}} \quad 1=$ if spouse has some college education or graduate studies

newengland ${ }^{\mathrm{a}}$ percentage of Hispanics living in PUMAS located in Connecticut, Maine, Massachusetts, New Hampshire, Rhode Island, Vermont

mideast $^{\mathrm{a}} \quad$ percentage of Hispanics living in PUMAS located in Delaware, District of Columbia, Maryland, New Jersey, New York, Pennsylvania

greatlakes $^{\mathrm{a}} \quad$ percentage of Hispanics living in PUMAS located in Illinois, Indiana, Michigan, Ohio, Wisconsin

plains $^{\text {a }} \quad$ percentage of Hispanics living in PUMAS located in Iowa, Kansas, Minnesota, Missouri, Nebraska, North Dakota, South Dakota

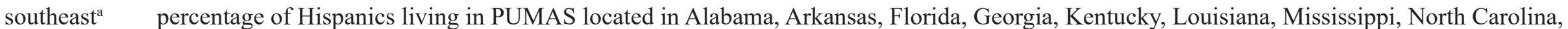

South Carolina, Tennessee, Virginia, West Virginia

southwest ${ }^{\mathrm{a}} \quad$ percentage of Hispanics living in PUMAS located in Arizona, New Mexico, Oklahoma, Texas. Reference group

rockym $^{\mathrm{a}} \quad$ percentage of Hispanics living in PUMAS located in Colorado, Idaho, Montana, Utah, Wyoming

farwest $^{\mathrm{a}} \quad$ percentage of Hispanics living in PUMAS located in California, Nevada, Oregon, Washington

$\operatorname{agmin}^{\mathrm{a}}$ 


\begin{tabular}{|c|c|}
\hline Variable & Description \\
\hline construc $^{\mathrm{a}}$ & percentage of Hispanics working in construction \\
\hline manuf ${ }^{a}$ & percentage of Hispanics working in manufacturing \\
\hline $\operatorname{trade}^{\mathrm{a}}$ & percentage of Hispanics working in trade \\
\hline transport $^{\mathrm{a}}$ & percentage of Hispanics working in transportation \\
\hline inform $^{\text {a }}$ & percentage of Hispanics working in information \\
\hline finance $^{\mathrm{a}}$ & percentage of Hispanics working in finance \\
\hline profserv $^{\mathrm{a}}$ & percentage of Hispanics working in professional services \\
\hline otherserv $^{\mathrm{a}}$ & percentage of Hispanics working in other services. Reference group \\
\hline pwhite & share of US born whites at the PUMA level \\
\hline pblack & share of US born African-Americans at the PUMA level \\
\hline pminorit & share of other US-born minorities at the PUMA level \\
\hline pimmigrant & share of other immigrants at the PUMA level \\
\hline pselfemp & share of self-employed individuals at the PUMA level \\
\hline punemployed & share of unemployed individuals at the PUMA level \\
\hline pcollege & share of individuals with college or higher education at the PUMA level \\
\hline
\end{tabular}

${ }^{a}$ The mean value for dummy variables represents the percentage of individuals showing that characteristic. 
required in buildings, and cooling degree-days measure the frequency in which the temperature is high enough that air conditioning is needed in the buildings.

In addition to being a flexible way of adjusting for non-randomness in the effect of Hispanic clustering on Hispanic self-employment, the generalized propensity score approach also provides us with a continuously varying treatment response: a dose-response function. This allows us to assess the extent to which the impact of Hispanic clustering on Hispanic self-employment is nonlinear.

\section{Results}

\section{Descriptive Statistics}

Approximately $8.5 \%$ of Hispanics in our sample are self-employed, compared to $11.1 \%$ of white US-born non-Hispanics, $12.6 \%$ of non-Hispanic immigrants, and $4.6 \%$ of black US-born non-Hispanics. Among Hispanics, first-generation Hispanics are the most entrepreneurial with $11.6 \%$ owning a business, followed by the 1.5 generation $(8.3 \%)$, the third generation $(6.7 \%)$, and the second-generation $(2.8 \%)$. The share of Hispanics living in a PUMA ranges from $0.2 \%$ to $96.8 \%$ with a mean of $13.5 \%$.

The average age for Hispanics in the 2010 census is 39 years old. As expected, first generation Hispanics are the oldest group with an average age of 43 years, followed by the third generation (39 years old), the 1.5 generation (36 years old), and the second-generation ( 25 years old). On average, $52 \%$ of Hispanics are married and have 1 child. While $13 \%$ of Hispanics have a college education or higher, educational attainment varies across Hispanic generations. The third generation has the highest proportion of college-educated Hispanics (17\%), which is significantly higher than first-generation Hispanics . On the other hand, only a minority of the respondents' parents have a college education $(2 \%)$ or have been self-employed (2\%). Approximately, $32 \%$ of their spouses are employed, $17 \%$ have at least a college education, and 39\% are Hispanic.

Over $80 \%$ of Hispanics are English-proficient and a similar proportion speak Spanish at home. When looking at the group of entrepreneurs, our sample suggests that the proportion of Spanish-speakers $(84 \%)$ is higher than English-proficient (69\%) Hispanics. As expected, first-generation Hispanics are significantly more Spanish-fluent than other generations . Conversely, first-generation Hispanics are significantly less English-proficient than other generations .

Similar to Parker (2004), over 91\% of Hispanics live in metro areas, and this is true for all generations. The proportion of Hispanics with mortgages is similar across gen- erations, but the second, third, and 1.5 generation are significantly different than first-generation Hispanics . There is a higher proportion of Hispanics that live in the Southwest (38\%), Far West (28\%), and Southeast regions (13\%). The vast presence of Hispanics in the south may be explained by the variety of policies and characteristics of these states that motivate Hispanics to live in well-established Hispanic communities (Kochhar et al., 2005).

\section{Regression Results}

This section answers two main questions: how does the probability of self-employment of any Hispanic change as Hispanic clustering increases, and how does Hispanic heterogeneity influence the probability of Hispanic self-employment. The first question is answered by looking at the parameter platino in Table 2 and the dose-response function in Figure 1. The relationship between Hispanic heterogeneity and Hispanic entrepreneurship is answered through Tables 3, 4, and 5 and in Figure 2 and 3. The probability to start a business for each generation of Hispanics as Hispanic clustering increases is shown by the coefficient of the interaction terms in Table 2 and the graph of the marginal effects in Figure 2. Table 3 shows the probability of self-employment for each generation, regardless of platino, and Table 4 shows how the clustering of each generation affects Hispanic entrepreneurship.

\section{How Does the Probability of Self-employment of any Hispanic Change as Hispanic Clustering Increases?}

Table 2 reports the coefficients and marginal effects from the standard probit and the instrumental variables probit. The left panel of Figure 1 shows the dose-response function from the GPS model, displaying how the average probability of self-employment varies depending on the (continuous) level of Hispanic clustering. The right panel of Figure 1 shows the treatment effect function, which is the derivative of the dose-response function with respect to the level of Hispanic clustering. We find that usual standard errors and robust standard errors are similar, which suggests that heteroskedasticity is not an issue. The results together provide robust empirical evidence that, on average, the probability of self-employment for Hispanics decreases as the share of Hispanics increases at the PUMA level, but this relationship is not necessarily linear.

The standard probit suggests that the average Hispanic is significantly less likely to start a business as the share of all Hispanics clustering in a PUMA increases. Contrary to Borjas (1986) and Wang (2010), this article provides empirical evidence that the clustering of Hispanics discourages 
the entrepreneurial motivation of Hispanics. One explanation is that Hispanic-dominated neighborhoods may suffer from limited resources possibly due to residential segregation. It is likely that Hispanic-dominated PUMAs may concentrate limited consumer demand, which can constrain the creation of Hispanic businesses. Further analysis indicates that employment, household income, and educational attainment proportionally decreases as the share of Hispanics increases. By concentrating Hispanics geographically, the decrease of Hispanic household income appears to deteriorate the entrepreneurial environment. It is likely that in PUMAs in which household income is below-average, there will be limited demand and an unfavorable business atmosphere. This finding supports the theory that Hispanic clustering can act as a mobility trap and harm Hispanic entrepreneurship (Borjas, 1983; Fischer \& Massey, 2000; Reimers, 1983).

The standard probit regression further shows that other factors are detrimental to Hispanic entrepreneurship, including financial factors, household characteristics, industry, and gender. Study results illustrate that Hispanics are less likely to be an entrepreneur as household income increases. In our sample, higher household income may be associated with broader labor market prospects among Hispanics. Thus, Hispanics with higher household income are less likely to be self-employed. Further factors deterring the probability that Hispanics enter self-employment are access to a mortgage and Hispanic ethnicity of the spouse . Hispanics working in agriculture, manufacturing, trade, information, or service industries are less likely to be self-employed. PUMAs with a high concentration of white USborn and non-Hispanic immigrants are environments that are detrimental to Hispanic entrepreneurial endeavors. Results provide evidence of a potential residential segregation and its negative effect on Hispanic entrepreneurial activity. Lastly, Hispanic women are less likely to be self-employed than men . This finding is supported by the literature that describes women's lower entrepreneurial activity due to lower human capital accumulation, motherhood penalty, and lower work-force participation rates (Fairchild, 2010; Marshall \& Flaig, 2014). The more human capital at the entrepreneur's disposal, the greater the odds of self-employment among Hispanics. Hispanics are more likely to be self-employed as the number of children increases, his/ her parents are self-employed, and the spouse is employed or has attended college. This may be due to the fact that age is associated with higher levels of human capital and access to financial capital that can improve the odds to start a business (Fairchild, 2010).

Hispanics living in metro areas, the Southeast, or in PUMAs with a high concentration of self-employed indi- viduals are more likely to start their own business. Well-established Hispanic communities in the south of the US may bring adequate resources, such as clientele, that motivate Hispanic entrepreneurship. Consistent with the literature, areas with vibrant entrepreneurial ecosystems can offer the clientele and resources that motivate Hispanics into self-employment (Liu, 2012; Wang, 2010).

The instrumental variable probit uses the Card (2009) and Coates and Gindling (2010) instruments to control for endogeneity from macroeconomic shocks that may induce Hispanic agglomeration. A key finding is that in the instrumental variable probit, the parameter is not statistically significant. The parameter represents the correlation between the errors in the standard probit and the reduced-form equation for the endogenous regressor. A that is not statistically significant is equivalent to saying that platino is unlikely to be endogenous. In other words, endogeneity is unlikely, and the results from the standard probit can be used to disentangle the effects of Hispanic clustering on the probability of self-employment. A reason why endogeneity is not an issue may be the extensive list of covariates included in the righthand side in the standard probit. The results from the instrumental variables probit are consistent with the standard probit, though the parameter estimates in the instrumental variables probit are somewhat larger in magnitude.

The GPS estimates of the dose-response function are shown in Figure 1; generally, we find that Hispanic entrepreneurial activity decreases as the share of Hispanics in a PUMA increases. Thus, the GPS method confirms the findings from the probit model. An important contribution from the dose-response and treatment effect functions is how Hispanic self-employment responds to a specific level of Hispanic clustering. Figure 1 points to three regions where the direction of the response of Hispanic entrepreneurship changes with respect to Hispanic clustering. In region $1(<$ $20 \%$ share of Hispanics) and region 3 ( $>80 \%$ share of Hispanics), Hispanic clustering has a positive or zero effect on the entrepreneurial activity of any Hispanic. A low and high concentration of Hispanics in the PUMA increases the probability of self-employment. Alternatively, Hispanics are less likely to start a business if living in PUMAs where the share of Hispanics is between $20 \%$ and $80 \%$ (region 2).

Further analysis shows that Hispanic-dominated PUMAs are mainly composed of foreign-born Hispanics with lower household income and educational credentials. For instance, Hispanic households living in low-concentrated PUMAs made on average $\$ 69,283$ while medium-concentrated and Hispanic-dominated PUMAs made \$54,346 and $\$ 54,754$ in 2010, respectively. Moreover, the higher the Hispanic clustering, the bigger the income gap between foreign-born and US-born generations. Hispanic-dominat- 
Table 2

Standard probit and IV probit results on the probability of Hispanic self-employment

\begin{tabular}{|c|c|c|c|c|c|c|c|c|}
\hline \multirow[b]{3}{*}{ platino } & \multicolumn{4}{|c|}{ Probit } & \multicolumn{4}{|c|}{ IV probit } \\
\hline & \multirow{2}{*}{$\begin{array}{c}\text { Coeff. } \\
-0.006\end{array}$} & \multirow[b]{2}{*}{$* *$} & \multicolumn{2}{|c|}{ Marginal Eff. $^{a}$} & \multirow{2}{*}{$\begin{array}{c}\text { Coeff. } \\
-0.014\end{array}$} & & \multicolumn{2}{|c|}{ Marginal Eff. } \\
\hline & & & -0.074 & $* *$ & & $*$ & -1.353 & $*$ \\
\hline lincome & -0.185 & $* * *$ & -2.450 & $* * *$ & -0.185 & $* * *$ & -18.497 & $* * *$ \\
\hline age & 0.063 & $* * *$ & 0.837 & $* * *$ & 0.063 & $* * *$ & 6.340 & $* * *$ \\
\hline agetwo & -0.001 & $* * *$ & $-b$ & & -0.001 & $* * *$ & $-b$ & \\
\hline crime & -0.001 & & -0.001 & & 0.000 & & -0.009 & \\
\hline nchild & 0.046 & $* * *$ & 0.609 & $* * *$ & 0.046 & $* * *$ & 4.593 & $* * *$ \\
\hline married & 0.053 & $* *$ & 0.699 & $* *$ & 0.052 & $* *$ & 5.241 & $* *$ \\
\hline speakenglish & -0.057 & $* *$ & -0.754 & $* *$ & -0.057 & $* *$ & -5.736 & $* *$ \\
\hline spanish & 0.054 & $* * *$ & 0.717 & $* * *$ & 0.056 & $* * *$ & 5.631 & $* * *$ \\
\hline female & -0.206 & $* * *$ & -2.726 & $* * *$ & -0.207 & $* * *$ & -20.657 & $* * *$ \\
\hline college & 0.033 & & 0.442 & & 0.034 & & 3.378 & \\
\hline metroarea & 0.131 & $* * *$ & 1.733 & $* * *$ & 0.143 & $* * *$ & 14.295 & $* * *$ \\
\hline accessmort & -0.037 & $* *$ & -0.493 & $* *$ & -0.038 & $* *$ & -3.774 & $* *$ \\
\hline collparent & -0.011 & & -0.146 & & -0.011 & & -1.132 & \\
\hline selfemppar & 0.487 & $* * *$ & 6.430 & $* * *$ & 0.488 & $* * *$ & 48.783 & $* * *$ \\
\hline employsp & 0.060 & $* * *$ & 0.796 & $* *$ & 0.060 & $* *$ & 5.997 & $* *$ \\
\hline sphispanic & -0.068 & $* * *$ & -0.900 & $* * *$ & -0.067 & $* * *$ & -6.686 & $* * *$ \\
\hline collspouse & 0.085 & $* * *$ & 1.125 & $* * *$ & 0.085 & $* * *$ & 8.490 & $* * *$ \\
\hline newengland & -0.023 & & -0.298 & & -0.009 & & -0.869 & \\
\hline mideast & 0.015 & & 0.204 & & 0.032 & & 3.205 & \\
\hline greatlakes & -0.054 & & -0.717 & & -0.042 & & -4.233 & \\
\hline plains & -0.038 & & -0.507 & & -0.033 & & -3.260 & \\
\hline southeast & 0.103 & $* * *$ & 1.355 & $* * *$ & 0.112 & $* * *$ & 11.170 & $* * *$ \\
\hline rockym & -0.064 & & -0.847 & & -0.059 & & -5.940 & \\
\hline farwest & 0.101 & $* * *$ & 1.334 & $* * *$ & 0.087 & $* *$ & 8.711 & $* * *$ \\
\hline agmin & -0.419 & $* * *$ & -5.535 & $* * *$ & -0.420 & $* * *$ & -42.033 & $* * *$ \\
\hline construc & 0.383 & $* * *$ & 5.058 & $* * *$ & 0.382 & $* * *$ & 38.241 & $* * *$ \\
\hline manuf & -0.811 & $* * *$ & -10.707 & $* * *$ & -0.811 & $* * *$ & -81.051 & $* * *$ \\
\hline trade & -0.170 & $* * *$ & -2.246 & $* * *$ & -0.170 & $* * *$ & -16.977 & $* * *$ \\
\hline transport & 0.001 & & 0.019 & & 0.002 & & 0.184 & \\
\hline inform & -0.435 & $* * *$ & -5.740 & $* * *$ & -0.434 & $* * *$ & -43.399 & $* * *$ \\
\hline finance & -0.018 & & -0.239 & & -0.017 & & -1.746 & \\
\hline profserv & -0.046 & $* *$ & -0.605 & $* *$ & -0.045 & $* *$ & -4.546 & $* *$ \\
\hline pamerican & -0.006 & $* *$ & -0.084 & $* *$ & -0.014 & $* *$ & -1.441 & $* *$ \\
\hline pblack & -0.002 & & -0.027 & & -0.010 & $*$ & -0.990 & $*$ \\
\hline pminority & -0.004 & & -0.049 & & -0.011 & & -1.124 & \\
\hline pimmigrant & -0.007 & $* *$ & -0.099 & $* *$ & -0.017 & $* *$ & -1.742 & $* *$ \\
\hline pselfemp & 0.039 & $* * *$ & 0.521 & $* * *$ & 0.041 & $* * *$ & 4.107 & $* * *$ \\
\hline
\end{tabular}




\begin{tabular}{|c|c|c|c|c|c|c|c|c|}
\hline punemployed & -0.006 & & -0.081 & & -0.006 & & -0.614 & \\
\hline pcollege & 0.003 & $* *$ & 0.043 & $* *$ & 0.003 & $* *$ & 0.281 & $* *$ \\
\hline constant & -0.898 & $* * *$ & - & & -0.127 & & - & \\
\hline Prob $>F$ & & & 0.00 & & & & 0.000 & \\
\hline athrho & & & - & & & & 0.022 & \\
\hline lnsigma & & & - & & & & 0.860 & $* * *$ \\
\hline N. Obs. & & & 111,132 & & & & 111,132 & \\
\hline
\end{tabular}

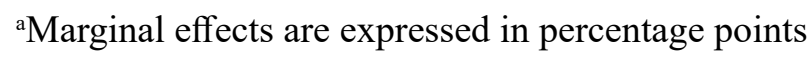

${ }^{\mathrm{b}}$ The marginal effects on variables that are not linear, that is interaction or quadratic variables, are omitted due to the lack of a parameter expressing the flexibility in the relationship between the variables.

Note: Asterisk $(*)$, double asterisk $(* *)$, and triple asterisk $(* * *)$ denote variables significant at $10 \%, 5 \%$, and $1 \%$ respectively.
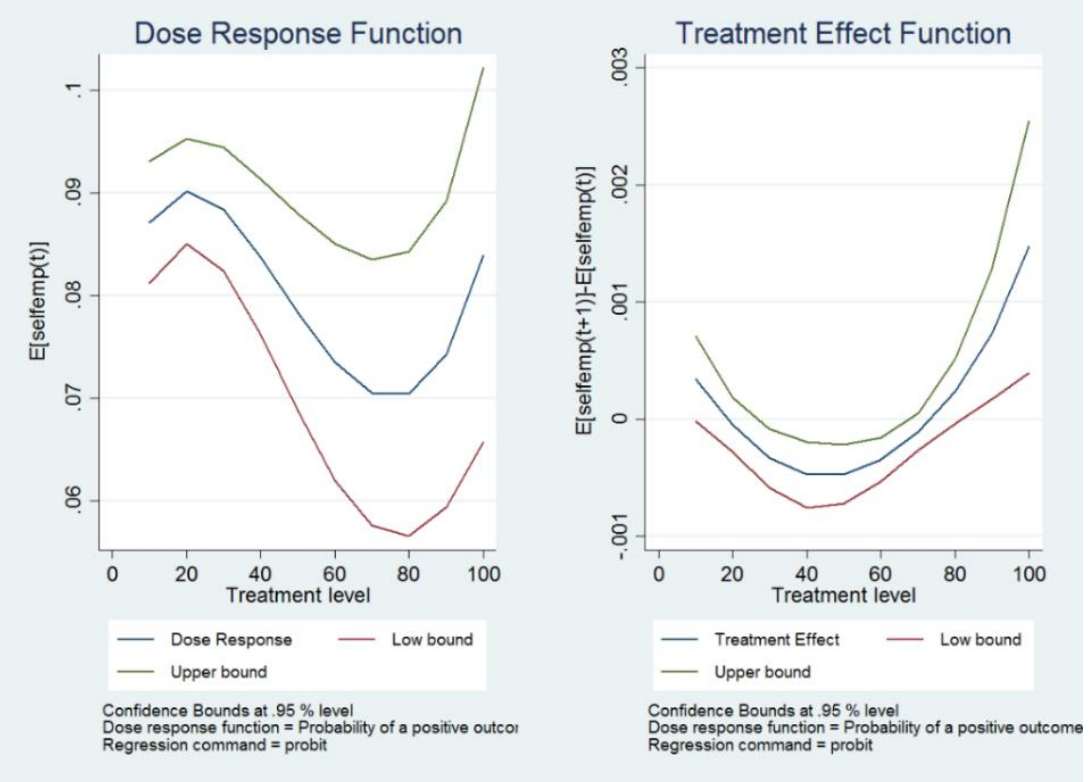

Figure 1. Dose-Response Function on the Effects of Hispanic Clustering on the Entrepreneurial Activity of an Average Hispanic

ed PUMAs have below-average levels of self-employment and individuals with college education.

\section{How Does Heterogeneity Among Hispanics Influence the Probability of Hispanic Self-Employment?}

One of the main goals of the article is to understand the role of Hispanic heterogeneity on entrepreneurship. First, we investigate whether the probability of self-employment varies across generations. Second, we investigate how the share of different generations of Hispanics within the PUMA influences the probability that Hispanics become self-employed. Table 2 displays the coefficients for interac- tion between platino and first, second, and third-generation Hispanics. The interaction coefficients in Table 2 measure the extent to which the probability to start a business varies across generations as the clustering of Hispanics increases. The coefficient estimates indicate that first-generation Hispanics are significantly more likely to start a business if they live in Hispanic-dominated PUMAs relative to 1.5 generation Hispanics. An explanation is that Hispanic-dominated PUMAs may encourage first-generation Hispanics to start a business by providing access to Hispanic clustering resources. On the other hand, second and third generation Hispanics are less likely to start a business as the clustering of Hispanics increases. Hispanic-dominated areas may be pushing US-born Hispanics out of self-employment and 
into wage-salary sectors due to the prospect of lower-revenue and lower-growth Hispanic-owned businesses.

Figure 2 illustrates the marginal effects of the interactions terms in Table 2 over the entire range of Hispanic clustering. Using Equation (1), Figure $2 \mathrm{a}, \mathrm{b}$, and c show how the probability of self-employment for first, second, and third-generation Hispanics, respectively, changes as the value of platino increases. In other words, this figure shows the relationship between self-employment and Hispanic clustering for first (a), second (b), and third (c) generation Hispanics over the range of Hispanic clustering. The

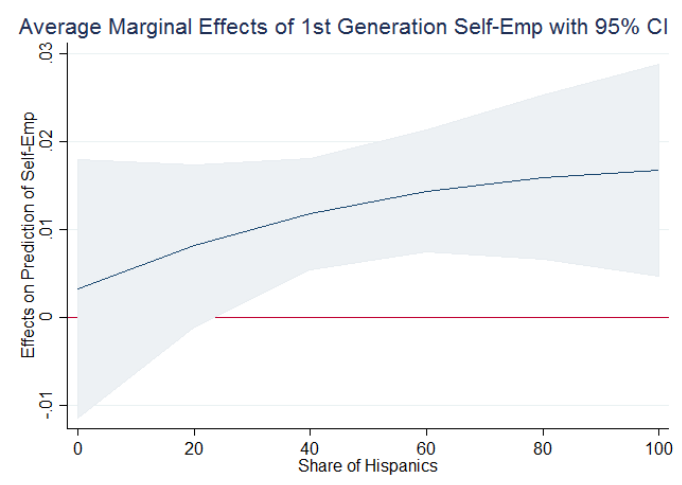

figure also illustrates the marginal effects with $95 \%$ confidence intervals. Similar to the coefficients in Table 2, Figure 2 illustrates that the probability of self-employment for first-generation Hispanics is positive, and it increases as the clustering of Hispanics increases. While the probability to start a business increases also for second and third-generation Hispanics, the probability of self-employment is negative at all levels of Hispanic clustering. In other words, the marginal effects indicate the true effect of Hispanic clustering on the probability of self-employment for first, second, and third-generation Hispanics.

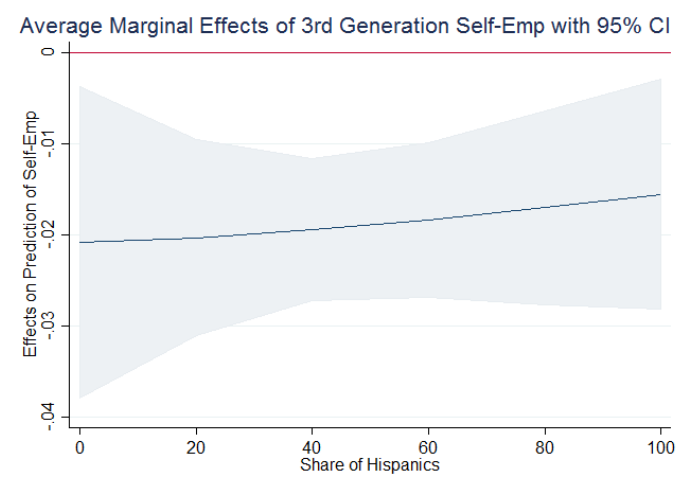

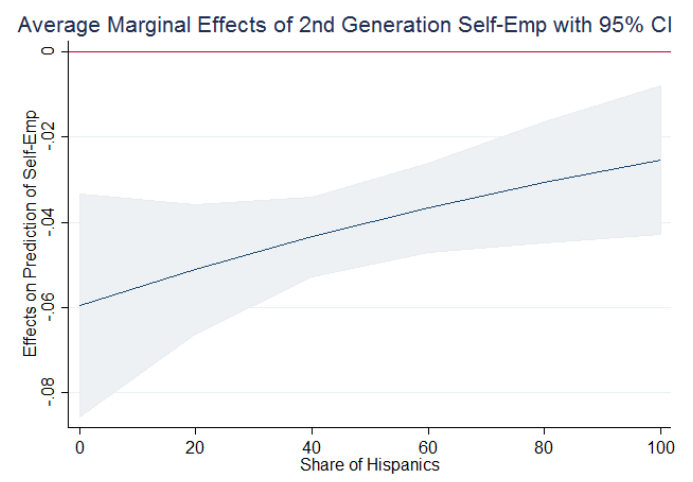

Figure 2. Marginal Effects on the Probability of Self-Employment for First (a), Second (b), and Third (c) Generation Hispanics as Hispanic Clustering Increases.

Table 3 demonstrates the probability of entrepreneurship for each generation, regardless of the clustering effect. Using Equation (1), Table 3 replaces the interaction terms with dummy variables if the respondent is first, second, and third-generation relative to the 1.5 generation. Table 3 shows the estimates and marginal effects of the probability of self-employment across generations of Hispanics. Similar to Model 1, the instrumental variables probit shows that endogeneity is not an issue, and the standard probit regression is interpreted below.

A key finding is that first-generation Hispanics are more likely to start a business relative to the 1.5 generation. One explanation is that first-generation Hispanics may face larger labor market constraints to enter the wage-salary sector than the 1.5 generation due to lower human capital. Georgarakos and Tatsiramos (2009) explain that many first-generation Hispanics enter self-employment from unemployment or underemployment. It is likely that first-generation Hispanics start their own business pushed by labor barriers and make use of clustering resources as a way out of poverty. On the other hand, second and third-generation Hispanics are less likely to be self-employed relative to the 1.5 generation .

We also investigate if there is a specific generation that drives the decrease in the probability to start a business for all Hispanics. Table 4 displays the probability that any His- 
Table 3

Standard probit results on the probability of self-employment across generations of Hispanics

Probit

Coeff.

Marginal Eff. ${ }^{a}$

\begin{tabular}{|c|c|c|c|c|}
\hline platino & -0.006 & $* *$ & -0.073 & $* *$ \\
\hline first & 0.075 & $* * *$ & 0.979 & $* * *$ \\
\hline second & -0.359 & $* * *$ & -4.672 & $* * *$ \\
\hline third & -0.136 & $* * *$ & -1.777 & $* * *$ \\
\hline lincome & -0.173 & $* * *$ & -2.259 & $* * *$ \\
\hline age & 0.055 & $* * *$ & 0.712 & $* * *$ \\
\hline agetwo & 0.000 & $* * *$ & $-b$ & \\
\hline crime & 0.000 & & -0.001 & \\
\hline nchild & 0.042 & $* * *$ & 0.543 & $* * *$ \\
\hline married & 0.036 & & 0.471 & \\
\hline speakenglish & 0.027 & & 0.357 & \\
\hline spanish & -0.012 & & -0.157 & \\
\hline female & -0.203 & $* * *$ & -2.644 & $* * *$ \\
\hline college & 0.035 & & 0.450 & \\
\hline metroarea & 0.121 & $* * *$ & 1.580 & $* * *$ \\
\hline accessmort & -0.047 & $* * *$ & -0.615 & $* * *$ \\
\hline collparent & 0.006 & & 0.084 & \\
\hline selfemppar & 0.549 & $* * *$ & 7.159 & $* * *$ \\
\hline employsp & 0.068 & $* * *$ & 0.881 & $* * *$ \\
\hline sphispanic & -0.087 & $* * *$ & -1.139 & $* * *$ \\
\hline collspouse & 0.094 & $* * *$ & 1.220 & $* * *$ \\
\hline newengland & -0.052 & & -0.679 & \\
\hline mideast & -0.010 & & -0.133 & \\
\hline greatlakes & -0.069 & & -0.894 & \\
\hline plains & -0.070 & & -0.909 & \\
\hline southeast & 0.064 & $* *$ & 0.831 & $* *$ \\
\hline rockym & -0.080 & & -1.039 & \\
\hline farwest & 0.088 & $* * *$ & 1.145 & $* * *$ \\
\hline agmin & -0.421 & $* * *$ & -5.482 & $* * *$ \\
\hline construc & 0.374 & $* * *$ & 4.875 & $* * *$ \\
\hline manuf & -0.815 & $* * *$ & -10.614 & $* * *$ \\
\hline trade & -0.165 & $* * *$ & -2.152 & $* * *$ \\
\hline transport & 0.010 & & 0.134 & \\
\hline inform & -0.413 & $* * *$ & -5.384 & $* * *$ \\
\hline finance & -0.006 & & -0.076 & \\
\hline profserv & -0.037 & $*$ & -0.482 & $*$ \\
\hline pwhite & -0.007 & $* *$ & -0.087 & $* *$ \\
\hline pblack & -0.003 & & -0.035 & \\
\hline
\end{tabular}




\begin{tabular}{lrr} 
pminority & -0.003 & -0.033 \\
pimmigrant & $-0.008 * *$ & $-0.108 * *$ \\
pselfemp & $0.040 * * *$ & $0.518 * * *$ \\
punemployed & -0.007 & -0.091 \\
pcollege & $0.003 * *$ & $0.036 * *$ \\
constant & $-0.718 * *$ & -0.00 \\
\hline Prob>F & & 111,132 \\
N. Obs. & \\
\hline Data source: 2010 census. & \\
${ }^{a}$ The marginal effects are expressed in percentage points. \\
${ }^{b}$ Marginal effects on quadratic variables are omitted due to the lack of a parameter expressing the flexibility in the rela- \\
tionship between the variables. \\
Note: Asterisk $(*)$, double asterisk $(* *)$, and triple asterisk $(* * *)$ denote variables significant at $10 \%, 5 \%$, and $1 \%$ respec- \\
tively.
\end{tabular}

panic becomes self-employed as the share of first, 1.5, second, or third-generation Hispanics increases. For the sake of simplicity, Table 4 only illustrates the key explanatory variables and excludes the set of covariates .

Table 4 illustrates the key variables of four probit regressions. Each regression replaces platino with the share of each generation pfirst, ponehalf, psecond, and pthird, respectively. The instrumental variables probit shows that endogeneity is not an issue, and we use the results from the standard probit regression. This suggests an intergenerational Hispanic clustering effect for Hispanic self-employment.

\section{Table 4}

Standard probit results

The probability that the share of each generation of Hispanics influences the decision to self-employment.

\section{Probit}

\section{Coeff. Marginal Eff. ${ }^{\mathrm{a}}$}

\begin{tabular}{lllll} 
pfirst & 0.001 & & 0.011 & \\
ponehalf & -0.003 & & -0.036 & \\
psecond & -0.005 & $* *$ & -0.071 & $* *$ \\
pthird & -0.001 & & -0.012 & \\
\hline
\end{tabular}

${ }^{\text {a }}$ Marginal effects are expressed in percentage points. Note: Asterisk (*), double asterisk (**), and triple asterisk $(* * *)$ denote variables significant at $10 \%, 5 \%$, and $1 \%$ respectively.

Our results, consistent with a growing body of literature (Fairchild, 2010), show that generational clustering has an effect on Hispanic self-employment. The results provide evidence that the clustering of second-generation Hispanics drives the decline of entrepreneurial activity among all Hispanics. Thus, second-generation clustering can be used as an indicator of the Hispanic entrepreneurial environment. An explanation for the negative effect of second-generation clustering is that their socioeconomic behavior is probably the most divergent due to assimilation and economic mobility, compared to first-generation Hispanics. Thus, increasing the proportion of second-generation Hispanics may be causing co-ethnic segregation. Intergenerational segregation will likely decrease the social and economic interaction between foreign-born and US-born Hispanics. Reduced intergenerational interaction in US-born-dominated PUMAs is likely to shrink the entrepreneurial atmosphere for foreign-born Hispanics. This assumption is echoed in Fairchild (2010): the clustering environment and intergenerational interaction significantly influence ethnic entrepreneurship. These results suggest that clustering resources, market conditions, and social norms that can encourage Hispanic entrepreneurship are minimal in neighborhoods dominated by second-generation Hispanics.

\section{Conclusions and Implications}

The US Census Bureau projects that by 2060, one out of three Americans will be Hispanic. If Hispanics are twice as likely to start a business as native-born Americans, it is likely that Hispanics will help define the US entrepreneurial landscape in the coming years. However, different studies define Hispanics differently: some articles define Hispanics as those that migrate from Latin America, and others consider Hispanics to be any foreign- or US-born individuals of Hispanic descent. Before designing policies, decision-makers should first recognize the heterogeneity among Hispanics and how policies may affect different groups of Hispanics differently. It is also unclear what motivates Hispanics to become entrepreneurs. 
One major contribution of this article is the empirical evidence related to Hispanic heterogeneity. While most studies lump Hispanics together in a homogeneous group, we advance the literature by focusing on Hispanic heterogeneity. Using census data, we derive insight on the labor choices for different generations of Hispanics. This article proposes that generational differences across immigrants is not merely an ethnic control factor, but rather an important factor for the design of strategies and incentives at the federal, state, and local level. Effective policies should focus on these generational differences to accurately promote success among Hispanic entrepreneurs.

The American Dream is the story of immigrants arriving to the US to find better opportunities. Many Hispanics are able to achieve economic mobility, but we find that different generations of Hispanics make different labor choices. While first-generation Hispanics are the most entrepreneurial group of Hispanics, they have on average lower income, education, and English proficiency than US-born Hispanics. Kramer Mills et al. (2018) reports Hispanic entrepreneurs to be the second-most dominant group among low-income entrepreneurs. We expect that policies that support low-income entrepreneurs will likely assist first-generation Hispanics more profoundly than other generations.

Most foreign-born Hispanic businesses are related to manual low-skilled sectors, especially construction and manufacturing. It seems that entrepreneurship is the way out of poverty for many Hispanics but can also be a source of employment for many low-wage workers. Hispanic-owned businesses, which tend to be located in low-income inner-city communities, may be helping reduce unemployment and poverty at the community level. Our results are consistent with Kramer Mills et al. (2018), who reported that many new Hispanic business ventures tend to be concentrated in economically depressed areas.

While entrepreneurship can be the ladder out of poverty for foreign-born Hispanics and their communities, they are likely to experience different obstacles to success than US-born entrepreneurs. Lack of access to capital and training, work regulations, and a high failure rate are among the most common barriers to Hispanic entrepreneurs (Kramer Mills et al., 2018). Targeted policies and incentives that provide training, education, and information to low-income immigrant entrepreneurs may be one way of helping immigrant entrepreneurs to succeed while shrinking poverty and expanding prosperity in economically-depressed communities. Policies that assist immigrant entrepreneurs through the strengthening of ethnic communities, access to resources, and bilingual information could improve the socioeconomic status of Hispanics and their communities.

The communities where immigrants live matter. Re- sults show that Hispanic entrepreneurship significantly depends on the clustering of Hispanics. A low and high degree of clustering in Hispanic communities encourage Hispanics to start their own businesses. These communities may be bringing social resources or offering niche markets that encourage Hispanics to create businesses.

Our results suggest the existence of a potential indicator for the Hispanic entrepreneurial environment. The agglomeration of second-generation Hispanics seems to be driving the decline of Hispanic entrepreneurship at the PUMA level. A major policy implication is that policymakers should consider policies that encourage social and economic interaction between foreign- and US-born immigrants. Increasing intergenerational bonds and social resources is likely to improve the entrepreneurial atmosphere for Hispanic entrepreneurs.

We also directly address identification issues in the ethnic clustering literature by applying a series of robust econometric techniques to census data. We develop econometric procedures to address the potential endogeneity between social interactions and individual economic behavior. Our identification strategy addresses several sources of potential endogeneity such as macro, individual, and peer unobserved characteristics that may affect the probability of self-employment and Hispanic clustering. This econometric procedure yields consistent results and allows us to draw causal conclusions on the main drivers of Hispanic entrepreneurship. Researchers and policymakers can use our findings to increase the availability and efficiency of community-based programs to encourage immigrant entrepreneurship.

Further research should investigate other sources of heterogeneity such as nationality and its interaction with generational differences. We expect that Hispanics from Mexico and Central America are likely to make different economic decisions than those from South America and the Caribbean. Future research should also focus on the role of government-sponsored and community-based organizations to offset the barriers to entrepreneurship and support credit access for Hispanic entrepreneurs. Many strategies can emerge from the interaction of local organizations and immigrants to provide the resources needed to start a business. While we do not focus on the legal barriers to immigrant entrepreneurship, this article can be helpful for understanding Hispanic entrepreneurship. Researchers and policymakers can use this article to advocate for ideas at the local, state, and federal level that aim to capture the economic gains from immigrant entrepreneurship. 


\section{References}

Amit, R., \& Muller, E. (1995). "Push" and "pull" entrepreneurship. Journal of Small Business \& Entrepreneurship, 12(4), 64-80.

Borjas, G. J. (1983). The substitutability of black, Hispanic, and white labor. Economic Inquiry, 21(1), 93-106.

Borjas, G. J. (1986). The self-employment experience of immigrants. The Journal of Human Resources, 21(4), 485-506.

Bradley, D. E. (2004). A second look at self-employment and the earnings of immigrants. International Migration Review, 38(2), 547-583.

Brock, W. A., \& Durlauf, S. N. (2001). Discrete choice with social interactions. The Review of Economic Studies, 68(2), 235-260.

Brock, W. A., \& Durlauf, S. N. (2007). Identification of binary choice models with social interactions. Journal of Econometrics, 140(1), 52-75.

Card, D. (2009). How immigration affects US cities. In R. P. Inman, (Ed.), Making cities work: Prospects and policies for urban America (pp. 158-200). Princeton University Press.

Charles, C.Z. (2003). The dynamics of racial residential segregation. Annual Review of Sociology, 29(1), 167-207.

Clark, K., \& Drinkwater, S. (2000).Pushed out or pulled in? Self-employment among ethnic minorities in England and Wales. Labour Economics 7(5), 603-628.

Coates, D. \& Gindling, T. H. (2010). Are Hispanic immigrant families reviving the economies of america's small towns? (IZA Discussion Paper No. 4682).

Cromie, S. (1987). Similarities and differences between women and men business proprietorship. International Small Business Journal 5(3), 43-60. http://papers. ssrn.com/sol3/papers.cfm?abstract_id $=1545109 \# \#$

Danes, S. M., Lee, J., Stafford, K. \& Heck, R. K. Z. (2008). The effects of ethnicity, families and culture on entrepreneurial experience: An extension of sustainable family business theory. Journal of Developmental Entrepreneurship, 13(03), 229-268.

Dávila, A., \& Mora, M. (2013). Hispanic Entrepreneurs in the 2000s: An economic profile and policy implications. Stanford University Press.

Durlauf, S.N. (2004). Neighborhood effects. In J. V. Henderson \& J. F Thisse, (Eds.), Handbook of regional and urban economics (pp. 2173-2242). Elsevier.

Evans, D. S., \& Leighton, L. S. (1989). Some empirical aspects of entrepreneurship. The American Economic Review, 79(3), 519-535. Fairchild, G. B. (2010). Intergenerational ethnic enclave influences on the likelihood of being self-employed. Journal of Business Venturing, 25(3), 290-304. Fairlie, R. W. (2004). Race and the digital divide. Contributions in Economic Analysis \& Policy, 3(15), 1-38.

Fischer, M. J., \& Massey D. S. (2000). Residential segregation and ethnic enterprise in U.S. metropolitan areas. Social Problems, 47(3), 408-424.

Fisher, M., \& Lewin, P. A. (2018). Push and pull factors and Hispanic self-employment in the USA. Small Business Economics, 51(4), 1055-1070.

Georgarakos, D., \& Tatsiramos, K. (2009). Entrepreneurship and survival dynamics of immigrants to the U.S. and their descendants. Labour Economics, 16(2), 161-170.

Kim, P., \& Aldrich, H. (2005). Social capital and entrepreneurship. Now Publishers Inc.

Kochhar, R., Suro, R., \& Tafoya, S. (2005). The New Latino South: The Context and Consequences of Rapid Population Growth. Pew Hispanic Center Report.

Kramer Mills, C., Battisto, J., Lieberman, S., Orozco, M., \& Lee, N. S. (2018). Latino-owned businesses: Shining a light on national trends. Stanford Business. https://www.gsb.stanford.edu/sites/ gsb/files/publication-pdf/slei-report-2018-latinoowned-businesses-shinging-light-national-trends.pdf

Lazear, E. (1999). Culture and language. Journal of Political Economy, 107(6), S95-S126.

Liu, C. Y. (2012). Intrametropolitan opportunity structure and the self-employment of Asian and Latino immigrants. Economic Development Quarterly, 26(2), 178-192.

Manski, C. F. (1993). Identification of endogenous social effects: The reflection problem. The Review of Economic Studies, 60(3), 531-542.

Marshall, M. I., \& Flaig, A. (2014). Marriage, children, and self-employment earnings: An analysis of self-employed women in the US. Journal of Family and Economic Issues, 35(3), 313-322.

Miguel, E., Satyanath, S., \& Sergenti, E. (2004). Economic shocks and civil conflict: An instrumental variables approach. Journal of Political Economy, 112(4), 725-753.

Parker, S. C. (2004). The economics of self-employment and entrepreneurship. Cambridge University Press.

Portes, A., \& Rumbaut, R. G. (2003). Children of immigrants longitudinal study. [Conference session]. The Immigrant Second Generation in North America and Europe. Bellagio, Italy. Reimers, C. W. (1983). Labor market discrimination against Hispanic and black men. The Review of Economics and Statistics, 65(4), 570-579.

Robinson, P. B., \& Sexton, E. A. (1994). The effect of education and experience on self-employment success. Journal of Business Venturing, 9(2), 141-156. 
Shapero, A., \& Sokol, L. (1982). The social dimensions of entrepreneurship. University of Illinois at Urbana-Champaign's Academy for Entrepreneurial Leadership Historical Research Reference in Entrepreneurship. https://ssrn.com/abstract=1497759

Shinnar, R. S., \& Young, C. A. (2008). Hispanic immigrant entrepreneurs in the Las Vegas metropolitan area: Motivations for entry into and outcomes of self-employment. Journalof Small Business Management, 46(2), 242-262.

Suro, R., \& Passel, J. S. (2003). The rise of the second generation: Changing patterns in Hispanic population growth. Pew Hispanic Center Report. Washington, DC.

USHCC (2015). Hispanic business \& entrepreneurs drive growth in the new economy. http://regionalhispaniccc.org/wp-content/uploads/2016/02/HispanicBusinessReport2015.pdf

Wang, Q. (2010). Immigration and ethnic entrepreneurship: A comparative study in the United States. Growth and Change, 41(3), 430-458.

Yuengert, A. M. (1995). Testing hypotheses of immigrant self-employment. Journal of Human Resources, 30(1), 194-204. 